\title{
Gather Wisdom and Strength of the Whole Society with the Spirits of Model, Labor and Craftsman
}

Su Yong

Shanghai Polytechnic University, Shanghai, 201209, China steady development of the whole society.

1 Overview of the spirits of model workers, labor and craftsmanship

\subsection{New connotation}

The spirits of model workers, labor and craftsmanship together mark a new banner in China in the new era. Under the guidance of these three spirits, a good atmosphere can be created effectively in the whole society and workers can be stimulated and motivated to learn from models and be in a model themselves so as to spur the great rejuvenation of Chinese nation ${ }^{[1]}$. General Secretary JinpingXi pointed out in the report addressed at The 19th National Congress of the Communist Party of China that efforts should be made to build an army of knowledge-based, skilled and innovative workers, carry forward the spirit of the model workers and craftsmanship to create a social fashion of work glory and a professional ethos of striving for perfection. In short, these three spirits arise from the development of China's history and are of distinctive Chinese marks. Along with the deepening and development of globalization, carrying forward the spirits of model workers, labor and craftsmanship can effectively promote Chinese traditional culture and unique Chinese culture brand to people all over the world and pushing China spirit to a greater world stage.

\subsection{Status and role}

The main functions of the spirits of model workers, labor and craftsmanship are as follows. Firstly, 
carrying forward these three spirits vigorously is favorable to creating domestic products better. Although China's economy has been greatly improved in recent years, there are still some problems compared with developed countries. Given the development of science and technology in China is not yet mature, it is very difficult for China to create domestic products. Vigorously carrying forward these three spirits can effectively transform this situation and urge China to create domestic products better. Secondly, carrying forward these three spirits can effectively promote economic transformation and upgradation of China [2]. The spirits of model workers, labor and craftsmanship embodies the main connotation of the socialist core values of China. Putting these three spirits to the development of enterprises in China can effectively motivate workers to carry better forward the socialist core values and promote the overall development of enterprises. Thirdly, vigorously carrying forward these three spirits will help to promote the supply-side structural reform and the reform of enterprises to the greatest extent. Because the supply-side structural reform is the most important road for small- and medium-sized enterprises in China, carrying forward these three spirits vigorously can play a leading role to the greatest extent, and make the mass people become the main force of the reform and development of enterprises in order to promote the stable development of state-owned enterprises in China.

\section{Problems arising from carrying forward the spirits of model workers, labor and craftsmanship}

First of all, with the development of society and the progress of science and technology, the ideological consciousness of Chinese people has also been changed greatly. Many people think that the education of children is the most beneficial way to Children's development, while this idea has drawbacks to a certain extent. Because many parents pay much attention to children's knowledge education, but ignore the importance of strengthening occupational technology for children. Because the eight-grade worker era has passed, secondary vocational school is no longer the first choice for students and parents, while it becomes the choice of parents whose children have done poorly in academic courses. Under such a passive situation, it is difficult for students and parents to attach importance to strengthening vocational and technical training. In the long run, it is also neither conducive to the development of vocational technology in China, nor to carrying forward the craftsmanship spirit. Secondly, occupational training in China has gradually lost importance as in the past. As a result, new technology graduates do not put enough emphasis on the work. Because students from vocational schools are generally with low academic quality, poor professional skills, and unclear ideological consciousness, these new graduates fail to develop a reasonable plan of future development and have weak sense of responsibility and unprofessional situation in their daily work. In the long run, it is not conducive to the development and inheritance of the spirits of model workers and craftsmanship. Finally, China's technology has achieved great progress in recent years. More and more high-tech digital devices have come into being as the times require, and have brought great convenience for engineering and production of small- and medium-sized enterprises. However, at the same time, China's traditional craftsmanship has been replaced. Digital technology is extended and developed from craftsmanship in the past. Though it improves product efficiency and raise economic profits of enterprises to a certain degree, it fails to present the main connotation of the craftsman spirit. Only by combining scientists' ideas, designers' drawings and the spirit of workers can a greater role be given to play and the promotion and inheritance of the spirit of labor, model workers and craftsmanship be propelled.

\section{Important countermeasures to gather wisdom and strength of the whole society}

\subsection{Pay attention to the connotation announcement the spirits of model workers, labor and craftsmanship} First of all, much attention should be paid to the 
spirits of model workers, labor and craftsmanship in order to gather wisdom and strength of the whole society. If emerging small- and medium-sized enterprises in China want to stand out in the same industry and develop the spirits of model workers, labor and craftsmanship in a better way, it is necessary to strengthen the intensity of connotation announcement to help every employee of enterprises feel the important impetus function of these spirits for enterprise development [3]. In addition, enterprises' employees also need to pay much more attention to the spirits of labor, model workers and craftsmanship, which serves as an important precondition to strengthen economic benefits of enterprises. Secondly, enterprises' leaders should give much more attention to the propagation of the connotations on these three spirits. In the spare time, it is necessary to set up a connotation information session, which helps to spread the spirits of model workers, labor and craftsmanship and mobilize all staff to participate in and understand the specific connotations of these spirits in an attempt to enhance their ideological level and help them work for enterprises in a better way. At last, the government should also pay attention to spreading the spirits of model workers, labor and craftsmanship. In addition to increasing the attention to these three spirits, such connotations should be infiltrated into small- and medium-sized enterprises gradually to perfect corporate culture, better adapt to the new ideology of socialism with Chinese characteristics raised by President JinpingXi in the new era and gather wisdom and strength of the whole society.

\subsection{Build high-quality talents training bases}

To gather wisdom and strength of the whole society and expand an enterprise by combining the spirits of model workers, labor and craftsmanship, one of the most important points is to strengthen the qualification and responsibility awareness of enterprises' employees. First of all, an enterprise should conduct professional training for existing employees. If necessary, outstanding professionals can be dispatched to study abroad and learn advanced management concepts abroad [4]. When they return home, these employees can combine ideas learned overseas with specific circumstances of the enterprise and the country's national conditions. As a result, they devote much to the spreading of the spirits of model workers, labor and craftsmanship in the enterprise so as to ensure the enterprise's professionalism. Meanwhile, the government also needs to build high-quality talent bases. Not only qualified personnel with higher education experience should be attracted, but those with very high professional skills should be hired. They should be trained in a unified way in an attempt to gather wisdom and strength of the whole society. Secondly, enterprises' leaders also need to improve self-quality of their employees. If an employee is found behaving poorly at work, such as tax evasion and kickbacks, such an employee can be fired instantly [5]. Outstanding employees with both good character and ability should be set up as examples in daily work and let other employees learn from them. This could help avoid worse scenarios caused by bad behaviors of employees which might occur during enterprise operation in the future [6]. Finally, enterprises' leaders need to strengthen their employees' sense of responsibility. Proper team activities or labor competitions can be carried out in daily work. The frequency of corporate team events should be increased. All of these measures can strengthen the cohesiveness of employees and help employees approve the developing concept of the enterprise and work for it better. Only by strengthening the quality and professional level of employees in an enterprise can the development and growth of the enterprise be propelled, and the wisdom and strength of the whole society gathered in a better way.

\subsection{Create a good corporate atmosphere}

Enterprises should take the initiative first to take actions to spread the spirits of labor, model workers and craftsmanship and also to gather the wisdom and strength of the whole society. Large-, mediumand small-sized enterprises in China rise up as China's economy develops gradually. In order to 
gather the wisdom and strength of the whole society and carry forward the spirits of labor, model workers and craftsman, the quality of enterprises' staff should be strengthened and a good corporate atmosphere created given enterprises are the place gathering talents. Therefore, enterprises should carry out the principle of "being people-oriented", strengthen construction of the core culture, build up the enterprising spirit of enterprises and publicize it vigorously to apply such a spirit in the whole system and links of human resource development and management. As a result, a kind of unity, enterprising and harmonious enterprise atmosphere can be created [7]. Thus, a strong corporate image can be established among all employees to develop unbreakable cohesion and closely link employees' development with an enterprise's targets. In addition, corporate culture should be reshaped. The culture of an enterprise is the core of an enterprise. The future trend and development of an enterprise depend on its corporate culture. Therefore, the traditional corporate culture should be transformed and a positive and advanced enterprise culture carried out in the development course of an enterprise. To increase employees' awareness of corporate culture in this way is of great importance.

\subsection{Foster a good atmosphere within which ability is given the top priority}

One of the important implements to gather wisdom and strength all over the nation is to foster a good atmosphere within which ability is given the priority. It is essential for Chinese government to emphasize the priority of ability in recruitment so as to popularize the spirits of labor, model workers and craftsmanship. This may in turn foster a good atmosphere which is mentioned above. Nowadays, as the education industry is gradually sophisticating in China, more and more parents would like to send their children to universities with good reputation, or even those abroad to get a good degree at any cost. However, the results are not very encouraging. Although many students do get their enviable degrees, they are not equipped with corresponding abilities. Consequently, the gap between graduates' abilities and their degrees remains unfilled ${ }^{[8]}$. In the meantime, technician graduates from vocational technology schools may be equipped with excellent work abilities in particular technical jobs and be able to work alone even though they show no advantage in terms of degrees ${ }^{[9]}$. Nevertheless, Chinese society has yet given enough attention to those technicians, who consequently could not get the according welfare that they are deserved to have. In the long run, it will not be helpful in terms of encouraging employment, fostering respect for model workers, or promoting quality workmanship. In a nutshell, fostering an atmosphere within which ability is given the priority in enterprises could not only balance the number of technicians and employees with higher degrees, but retain relevant technical professionals in order to better gather the wisdom and strength all over the society.

\subsection{Increase financial support from governments and enterprises}

To increase financial support from governments and enterprises is another important implement to gather the wisdom and strength of the whole society. The key element for China to encourage spirits of labor, model workers and craftsmanship is to strengthen governments' attention to it and urge governments to make practical moves to address specific issues in routine work ${ }^{[10]}$. Meanwhile, it is necessary for governments to increase investments to set prizes awarding model workers, who possess workmanship spirit, labor model spirit and hardworking spirit from the older generation and rehire them back to businesses in order to motivate every employee to carry forward these spirits with the power of models. Hence, the wisdom and strengths all over the society are gathered. Additionally, enterprises should set up a special fund to award employees who are extremely responsible in routine work. Setting those employees as models could better respond to the concrete connotation of China's spirits of labor, model workers and craftsmanship. It is clear that fostering these three spirits is a rather long and struggling process, which needs several generations' efforts. In this case, 
governments along with enterprises should pay attention to this in the long run and provide sufficient funds so as to better encourage the spirits of labor, model workers and craftsmanship and gather the wisdom and strengths all over the society.

\subsection{Carry out educational activities of model workers.}

To further promote the spirits of model workers, labor and craftsmanship and cultivate talents with these excellent qualities, universities should fulfill their responsibilities. They should carry out educational activities of model workers while cultivating students with knowledge and cultural literacy in order to equip talents with passion and responsibility in the workplace, courage to break new ground and sense of dedication in the new era. As a result, social civilization progress and national economic development will be promoted in this sense. Thus, application-oriented universities, especially those recognized by model workers culture centers, should carry out educational activities of model workers in the following two aspects. Each of the university can first, create a campus culture which embodies model workers culture symbols and establish a special campus culture brand with model workers cultural imprint by building a model workers alumni display wall or an innovation road exhibition hall. Second, hire alumni appraised as model workers back to universities as tutors, who advise students with their study problems and career choice and personal development issues. Above all, application-oriented universities should make full use of model effect to cultivate new era talents with the spirits of model workers, labor and craftsmanship.

\section{Conclusion}

Every labor model is a flag urging for improvement. Actions that promote the spirits of model workers, labor and craftsmanship are not only adopted to meet the development of modern society, but motivate the progress of the society and the development of civilization. Living in the big data era, China's special cultural spirit could be known by people from every corner of the world if the publicity of the spirits of model workers, labor and craftsmanship is enhanced. This paper analyzes the specific connotation of China's spirits of model workers, labor and craftsmanship in the new era and the relevant issues that the society is confronting and comes up with the following solutions. Preach about the connotation of the spirits of model workers, labor and craftsmanship; establish training centers aiming at cultivating high-quality talents; foster a good atmosphere within which ability is given the priority; and increase financial support from governments and enterprises. This may hopefully offer theoretical help for China to better promote the spirits of model workers, labor and craftsmanship.

\section{References}

[1] ChunhongWang, JiaGai. The Importance of Cultural Transmission of Work-model Spirit and Textile Culture[J]. Oriental Enterprise Culture, 2016,11(12):5-7. (in Chinese)

[2] WenLiu, YizheZhang. The Cultivation of the Spirit of Model Workers and The Value-based Leadership -A Summary of "The Spirits of Model Workers, Labor and Craftsmanship: The Academic Symposium on Value-based Leadership and Ideological and Theoretical Education[J]. Ideological \& Theoretical Education, 2017,12(05):110-111. (in Chinese)

[3] JianguoLi. Promote the Spirits of Model Workers, Labor and Craftsmanship and Achieve Good Results To Meet the 19th CPC National Congress-- A Speech at the Conference on Celebrating International Workers' Day and Awarding National Laborers and Pioneers of National Workers in 2017[J]. Chinese Workers, 2017,22(05):9-11. (in Chinese)

[4] QiaolingLiao, ShilongZhou. Compose "Three Spirits" into The Theme of Time-- An Interview with Municipal Committee and Chairman of the City Federation of Trade Unions of Xiangyang, WuCheng[J]. Fellow Workers, 2017,11(08):30-31. (in Chinese)

[5] RuiZhang. Contribute to The Innovation and Development of The Trade Union with Consolidated Ideal and Belief and Good Moral Behavior-- As Yufu 
Li Encouraged at The Speech in the Youth Forum Hold By All-- China Federation of Trade Unions on Promoting Craftsmanship Spirit and Build Success[J]. Chinese Workers, 2017,21(06):10. (in Chinese)

[6] JianguoLi. Promote the Spirits of Model Workers, Labor and Craftsmanship and Achieve Good Results To Meet the 19th CPC National Congress-- A Speech at the Conference on Celebrating International Workers' Day and Awarding National Laborers and Pioneers of National Workers in 2017[J]. Chinese Workers' Movement, 2017,22(05):4-7. (in Chinese)

[7] QuanXiao. "The King of Cars of Arsenal" in Northern Xingjiang-In Remembering the National Model Worker, Part-time Vice Chairman of Inner Mongolia Autonomous Region Federation of Trade Unions, Hydraulic Machinery Worker of Inner Mongolia North Heavy Industries Group, and Chief Weapon Technician, GuiyouZheng[J]. Trade Union
Information, 2016,21(06):9-12. (in Chinese)

[8] TiankaiWang. Speech at the Conference on AwardingNational Advanced Groups of Textile Industry, Model Workers, and Advanced Workers[J]. Oriental Enterprise Culture, 2016,22(07):11-16. (in Chinese)

[9] JinpingXi. Promoting Spirits of Model Workers and Labor All the Time To Gather Strong Positive Energy for China's Economic and Social Development[J]. Party Construction, 2015,22(05):1. (in Chinese)

[10] ChangxingXin. Promoting A Zeitgeist Honoring Workers and Creation of Great Things --In Studying and Implementing the Important Speech That President $\mathrm{Xi}$ Addressed at the Conference on Awarding National Model Workers[J]. Qiushi, 2015,11(10):22-23. (in Chinese) 